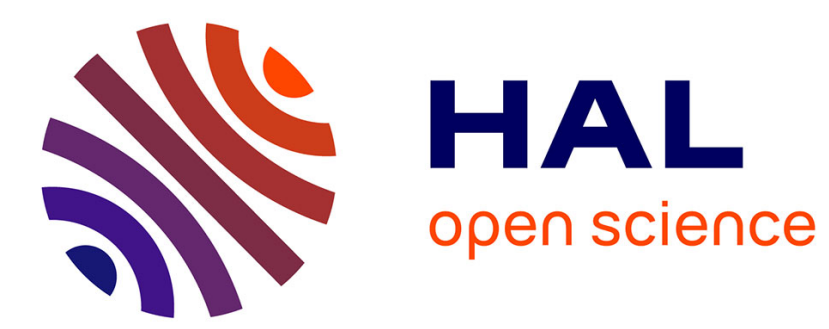

\title{
QUALIFICATION OF A RAMP-WAVE GENERATOR
}

Michel Perez

\section{To cite this version:}

Michel Perez. QUALIFICATION OF A RAMP-WAVE GENERATOR. Journal de Physique Colloques, 1988, 49 (C3), pp.C3-713-C3-719. 10.1051/jphyscol:19883101 · jpa-00227729

\section{HAL Id: jpa-00227729 https://hal.science/jpa-00227729}

Submitted on 1 Jan 1988

HAL is a multi-disciplinary open access archive for the deposit and dissemination of scientific research documents, whether they are published or not. The documents may come from teaching and research institutions in France or abroad, or from public or private research centers.
L'archive ouverte pluridisciplinaire HAL, est destinée au dépôt et à la diffusion de documents scientifiques de niveau recherche, publiés ou non, émanant des établissements d'enseignement et de recherche français ou étrangers, des laboratoires publics ou privés. 


\title{
QUALIFICATION OF A RAMP-WAVE GENERATOR
}

\author{
M. PEREZ \\ Centre d'Etudes de Gramat, F-46500 Gramat, France
}

Resume - Un presente un materiau generateur de rampe de compression quasiisentropique. Ce materiau est elabore par les techniques de la Metallurgie des Poudres sous la forme de disques plans de ' $2 \mathrm{~mm}$ d'epaisseur, qui presentent une variation quasi-lineaire de la densite et de l'impedance acoustique en fonction de L'épaisseur. L'ef'ticience de ce materiau a eté prouvee, notamment dans le tantale ou une rampe de contrainte de $84 \mathrm{GPa}$ et de yI0 ns de temps de montee, a ete mesuree a $1,84 \mathrm{~mm}$ de protiondeur. Un modele de comportement hydrodynamique de ce materiau est egalement présenté.

Abstract - A material has been developed for generating a quasi-isentropic compression wave in piate impact experiments. This material has been realized using powder metaliurgical techniques in the form of plates 2 mm-thick, which have a quasi-linear variation in density and acoustic impedance according to their - thickness. The efticiency of this material has been proved, particularly in tantalum where a ramp-wave of $8: 4$ GPa and a 910 nanoseconds rise time has been measured at $1.84 \mathrm{~mm}$ propagation distance. A hydrodynamic model of this material is also presented.

\section{1 - INTRODUCTION}

The equations of state of solid materials used in the range $0-100 \mathrm{GPa}$ and beyond are usually based on the Hugoniot adiabat. These equations are used, particulariy in numerical computer codes, to describe the material's behavior in thermodynamic states often of $f$ Hugoniot. A ramp-wave generating material, like the FILLWW /1/ developed by the Sandia Laboratories, open up wide possibilities in this f'ield in that they allow compression of solids according to a quasi-isentropic process. The ramp-wave generating material which is the subject of this paper is designated by the acronym MIVAR (Materiau d'Impedance Variable). This material has a gradua $\perp 1$ y decreasing acoustic impedance, and has been developed by a powder metallurgical techniques.

\section{2 - DESCRIPTION OF THE MIVAR}

The MIVAR is a composite material developed in col'laboration with the Material Research Center of the Ecole des Mines in Paris /2/, i.l the form of plates ' $z$ mthick and $50 \mathrm{~mm}$-diameter. It has a quasi-linear variation in dersity and in acoustic impedance according to its thickness, with a density limit of between 18.1 and 1.2 and an acoustic impedance ratio between the two taces of 29 . This material has three constituent parts. The first two parts, based on metal powders, have been elaborated by a technique known as "slurry paint technique" combined respectively with sintering and H.I.P.. Theses two parts are bonded together, and the third part consists of plastic layers deposited by a spray painting techrique. The MIVAR is developed on a tungsten alloy base 2 mm-thick, which has a density equal to 18.1 . This base plate has a dual purpose : it both guarantees the levelness of the MIVAF during its fabrication, particularly during the H.l.P. process, and makes it possible to withstand the ramp-wave produced in the target struck by the MIVAR.

The basic principle of the 'lllVAF is that it allows tor the substitution of the matter loaded by a single shock wave, with progressive loading by a series of long itudinal waves of weak amplitude. This principle is illustrated on f'igure 1 in cases where target material loading is either by ar impartor whose acoustic impedance de- 

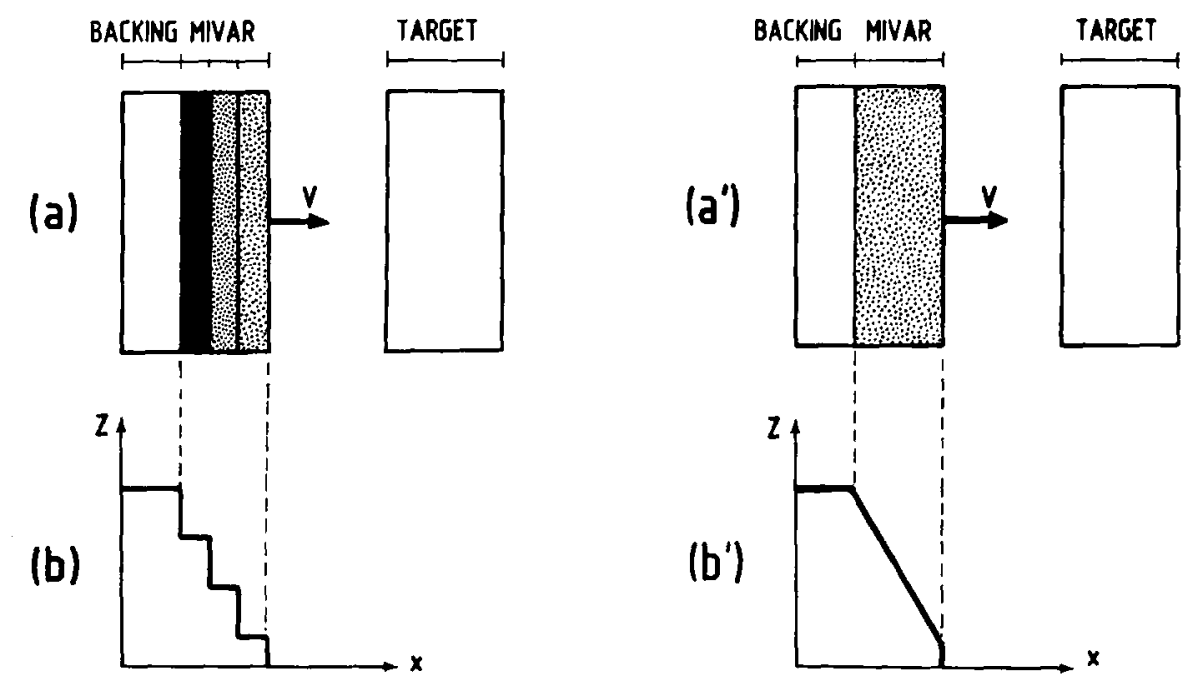

(c)
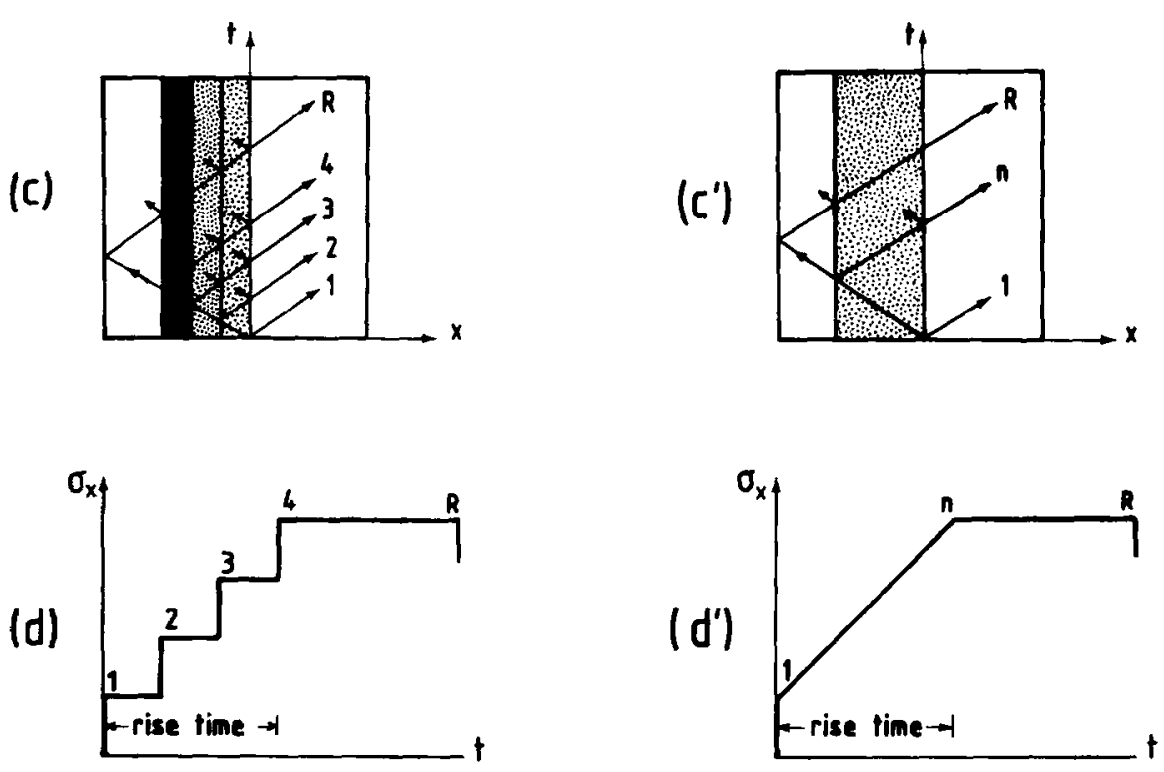

Figure I - Schematic representation of a plate-impact experiment in case where target material loading is either by an impactor whose acoustic impedance decreases in steps (a) or one with gradually decreasing impedance $\left(a^{*}\right)$. Experimental concepts (a,a ' ', acoustic impedance prof'iles of MIVARs $\left(b, b^{\prime}\right), X-t$ planes $\left(c, c^{\prime}\right)$, ramp-wave profiles in the targets $\left(d, d^{\prime}\right)$. 
creases in steps or one with gradually decreasing impedance. In this latter case, the target is loaded by successive weak compression waves which propagate through the target as a compression ramp-wave. Let us now consider the case of solid target materials. For laading that causes stresses beyond the yield limit, plastic waves are generated. Because of the irreversible nature of this phenomenon always present, the loading of solids by means of MIVAR type generators is called quasi-isentropic.

\section{3 - EXPERIMENTAL RESULTS}

We shall present here the results of two plate-impact experiments in which the MIVAR is accelerated in a smooth-bore gun to collide with a planar target material.. These experiments were pertormed by means of a cormpressed gas gun /3/ for test number 1018, and a powder gun /4/ for test number 24. The characteriatics of these experiments are given in table $I$.

Table I - Test conditions and experimental results.

\begin{tabular}{|c|c|c|c|c|c|c|}
\hline $\begin{array}{l}\text { test } \\
\text { number }\end{array}$ & $\begin{array}{l}\text { MIVAR } \\
\text { thickmess } \\
\text { (min) }\end{array}$ & $\begin{array}{c}\text { target } \\
\text { material }\end{array}$ & $\begin{array}{l}\text { impact } \\
\text { velocity } \\
\text { (m/s) }\end{array}$ & $\begin{array}{c}\text { measured } \\
\text { perticle velocity } \\
(\mathrm{m} / \mathrm{s}\}\end{array}$ & $\begin{array}{l}\text { calculated } \\
\text { stress } \\
\text { (GFa) }\end{array}$ & $\begin{array}{l}\text { rise } \\
\text { time } \\
\text { (ns) }\end{array}$ \\
\hline 1018 & 1.92 & fused silica & 564 & 515 & $5,86^{411}$ & 1280 \\
\hline 24 & 1.99 & $\mathrm{Ta} / \mathrm{LiF}$ & 2005 & 1772 & $84^{(2)}$ & 910 \\
\hline
\end{tabular}

(1) calculated from the stress-particle equation of fused silica given in ref".5.

(x) calculated firon the measured Ta-LiF interface velocity given in the table, by the impedance tching technique between tantalum /6/ and LiF/T/ target materials.

Figures 2 and 3 show the experimental arrangements and the particle velocity prot iles mensured which a ISAF interfercmeter. It shondid be roted that the ratpo-weste le smooth for higher impact welocities. The different steps occurring in the rawify ow figure 2 were contirmed by complementary experimente not show here. These resulis

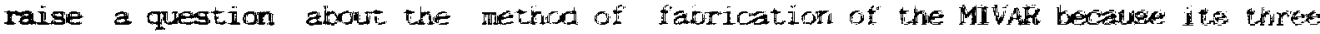
constituent parts met ite at tre origir of these trines guasi-etepe. Furthermore the

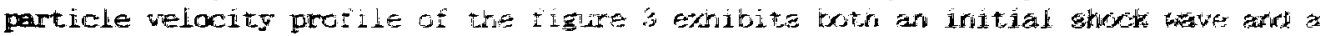

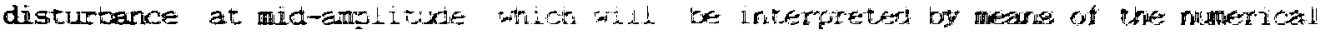

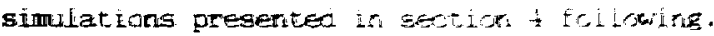

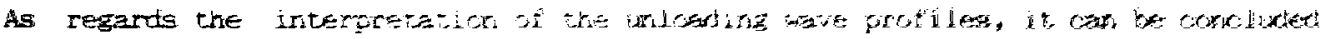

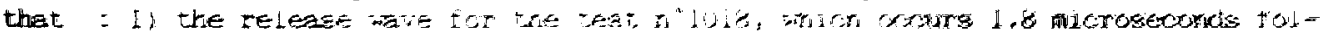

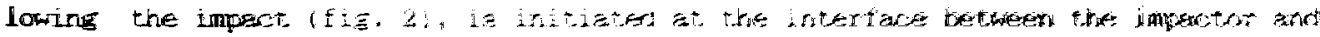

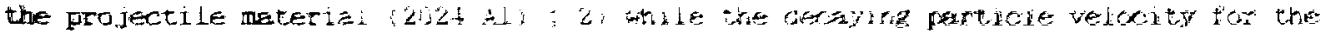

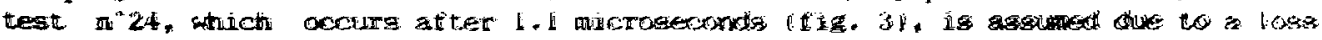

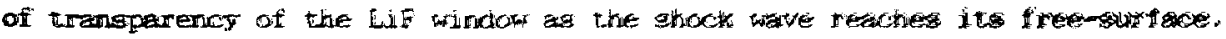

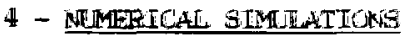

We have fomulated conetitutive equatone of the Mivf, both in order to interpret

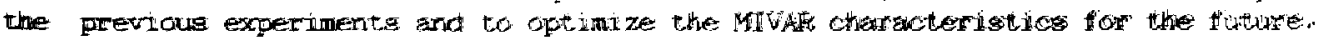

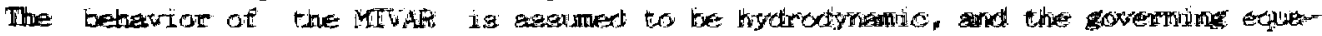

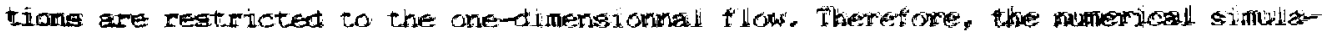

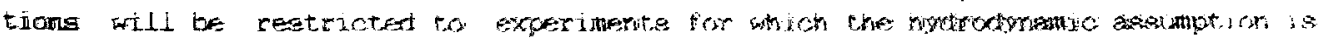
acceptable, thet is to those in which impact velocities are nigh enough. 


\section{1. - Theoretical model}

There are, to our knowledge, two radically difiering approaches to the problen of perceiving the stress wave response of a composite material like the MIVAR. The first, illustrated in Drumheller's work $/ 8 /$, is a micromechanical approach which considers the composite as a heterogeneous material constituted of several phases, and simulates its behavior by means of a computer code conceived for the treatment of multi-phase fllows. We have not used this approach as it requires both an adequate computer code and an accurate formulation of the complex mechanical interactions between the constitutive phases. The second approach is macromechanical and considers the composite as a macroscopically homogeneous material. The density, the Hugoniot adiabat, even the Gruneisen's gamma of the composite material are deduced from those of its constituents, from assumptions which are the basis for the theory developed by Tsou and Chou $/ 9 /$ in the case of fibered or layered composites, by Mc Queen et al /10/, Munson and Schuler /11/ and Hopkins /12/ in the case of powder mixtures. We have used this second approach for the simplicity of its formalism, and particularly the theoretical formulation derived by the two last investigators.

The model is based on the following tour fundamental assumptions : 1) we suppose that the MIVAR is constituted of 25 macroscopically homogeneous and isotropic layers ; 2) we suppose that the shock behavior of the MIVAR is hydrodynamic ; 3 ) we suppose that the pressure is uniform in the different components of a layer ; 4) finally, we suppose that the mass fractions of the components of a layer remain unchanged during the MIVAK's compression.

We propose the formulation of a constitutive equation for the MIVAR whose parameters can be adjusted for each one of the Layers. Mc Queen et al /10/ utilized a MieGrüneisen equation of state in which the parameters were derived from those of the components, assuming an interpolation rule between the values of the parameters for the individual components, based on the mass fraction of the constituents. For the room temperature Grineisen's ganura; Hopkins /12/ points out that this interpolation procedure is un.justified. To avoid this area of uncertainty, we use a strictly mechanical formulation of the constitutive equation, such as that utilized by Hopkins. This fornulation implicitly states that the thermal effects are ignored in the shocked MIVAR.

The density of a given layer of the MIVAR is given by the following equation in which $\alpha_{i}^{j}$ is the volume fraction of the $i^{t h}$ constituent of the $j^{\mathbf{t}}$ Layer, $p_{i}$ is the density of the $i^{\text {th }}$ constituent, $n$ is the number of constituents in the layer and $N$ is the number of layers of the MIVAR :

$$
p^{j}=\sum_{i=1}^{n} \alpha_{i}^{j} p_{i}, \quad j=1, N
$$

The ratio of this equation formulated at ambient pressure to the same equation formulated at a different pressure, defines implicitly the required equation of state. After reduction $/ 13 /$, we obtain :

$$
\frac{P_{0}^{j}}{\rho^{j}}=\sum_{i=1}^{n} \alpha_{0 i}^{j} \frac{P_{0 i}}{P_{i}}, \quad, j=1, N
$$

in which the subscript " $\circ$ " refers to conditions at ambient pressure. In order to express the pressure in this equation, we have defined the constituents of the MIVAR by a Murnaghan type equation whose parameters $A_{i}$ and $B_{i}$ are identified on the 
Hugoniot adiabats of the constituents :

$$
P=A_{i}\left\lfloor\left(\frac{P_{1}}{P_{01}}\right)^{B_{i}}-1\right\rfloor
$$

The equations (2) and (3) define the equations of state of the MIVAR's Layers. Rearranging these two equations we obtain :

$$
\frac{\rho_{0}^{j}}{p^{j}}=\sum_{i=1}^{n} \alpha_{0 i}^{j}\left(\frac{P}{A_{i}}+1\right)^{-\frac{1}{B_{i}}}, \quad j=1, N
$$

This relatively simple model is characterized by the following four parameters : the volume fractions and the densities of the constituents at ambient pressure, respectively $\alpha_{0 i}^{j}$ and $P_{0 i}$, and the two parameters $A_{i}$ and $B_{i}$.

\section{2 - Numerical resuits}

The above equation of state was introduced into a one-dimensionnal finite-difference computer code. To illustrate the capabilities of this model a representative calculation is presented here and compared to experimental result of the tegt number 24 defined in table $I$ and figure 3. The volumetric behavior of the materials nitene 181, lithium fluoride, and tantalum, were described in terms of a Mie-Grüneisen type equation of state. Furthermore the shear behavior of tantalum was taken into account using an elastic-perfectly plastic model following the method formulated by Wilkins /14/. The physical constants of these materials are given in table II.

Table II - Data for impactor (MIVAR apart) and target equations of state ${ }^{1,2}$

\begin{tabular}{lccccccc}
\hline material & $\begin{array}{c}\hat{P}_{0} \\
(\mathrm{~g} / \mathrm{cc})\end{array}$ & $\begin{array}{c}\mathrm{C}_{0} \\
(\mathrm{~m} / \mathrm{s})\end{array}$ & $S$ & $\gamma_{0}$ & $\begin{array}{c}\mathrm{Y}_{0} \\
(\mathrm{GPa})\end{array}$ & $\begin{array}{c}\mathrm{G}_{0} \\
(\mathrm{GPa})\end{array}$ & Rej. \\
\hline nitene 181 & 18.1 & 3970 & 1.23 & 1.43 & - & - & $/ 15 /$ \\
LiF & 2.64 & 5148 & 1.353 & 1.69 & - & - & $/ 16 /$ \\
tantalum & 16.66 & 3360 & 1.239 & 1.63 & 0.96 & 68.8 & $/ 17 /$ \\
\hline
\end{tabular}

(1) $u_{s}=C_{o}+S u_{p}: u_{S}$ and $u_{p}$ are respectively the shock velocity and particle velocity.

(2) $p_{0}$ is the initial density, $r_{0}$ is the Gruneisen's gamm, $y_{o}$ is the yield strength, and $G_{0}$ is the shear modulus.

The comparison between computational and experimental resulta ia depicted on figure 4. The computation is stopped at the peak of the particle velocity profile bscause the model cannot represent the remaining particle velocity as discussed in gection 3. The initial shock reproduced by the calculation corresponds to the elastic wave traveling in the tantalum, which has been confirmed by computation runs perf'ormad elsewhere. On the other hand, one can see that the large diaturbance at mid-estupli= tude of the experimental profile is not reprobuced by the gimulation. It is very probable, as discussed by Farker /1/, that the initial arseleration of the MIVAF during launching (about $3.10^{5} \mathrm{~m} / \mathrm{s}^{2}$, initiates tensile atraseses that cause the MJWA 


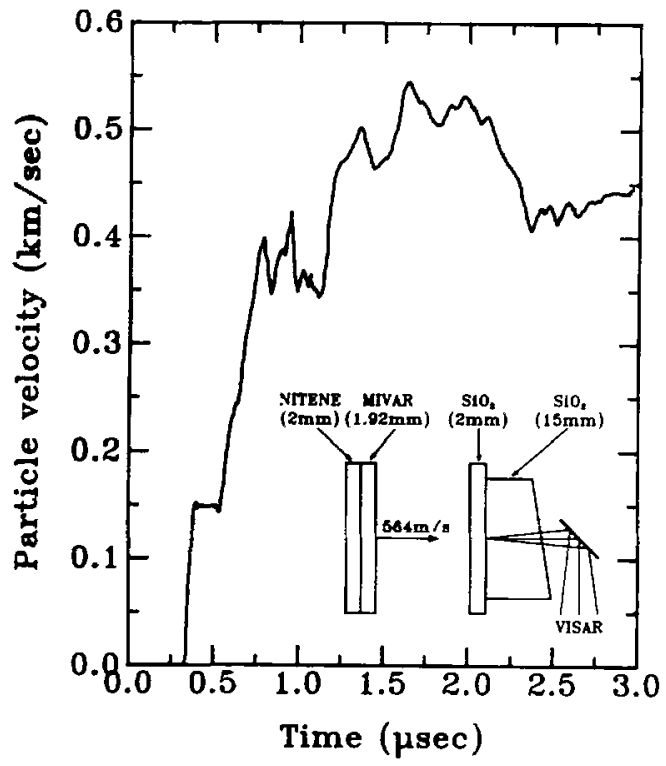

Figure 2 - Neasured particle velocity for experiment n"1018.

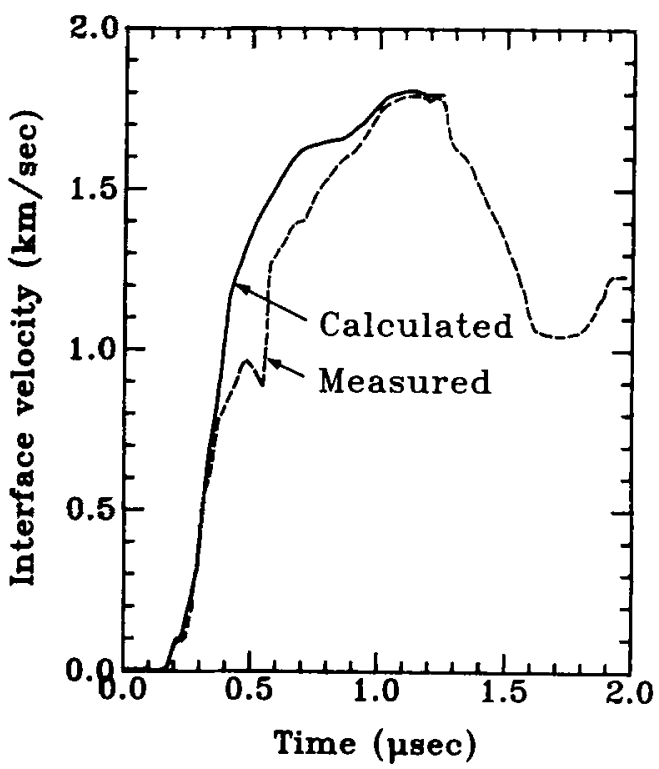

Figure 4 - Experiment n'24 - comparison between experimental and numerical particle velocity versus time without. numerical treatment of MIVAR spall.

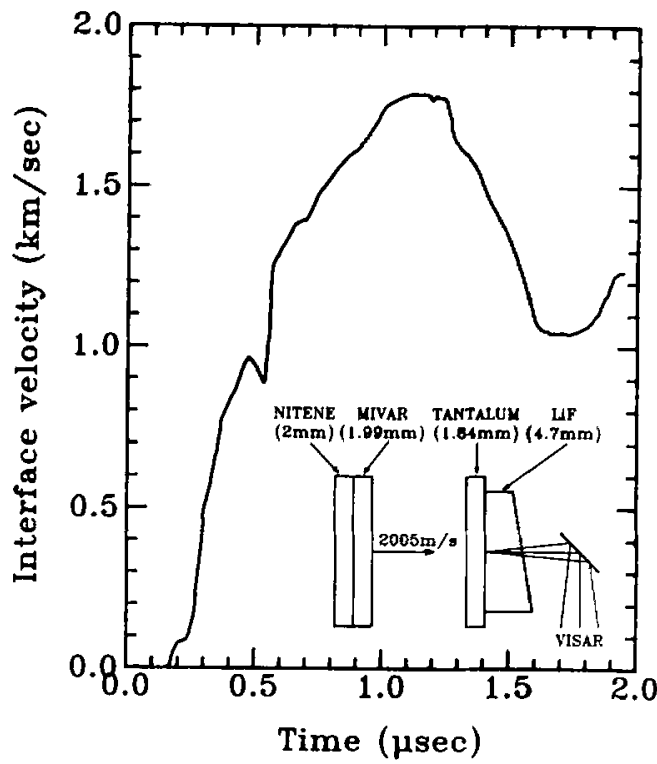

Figure 3 - Measured interface velocity for experiment n"' 24 .

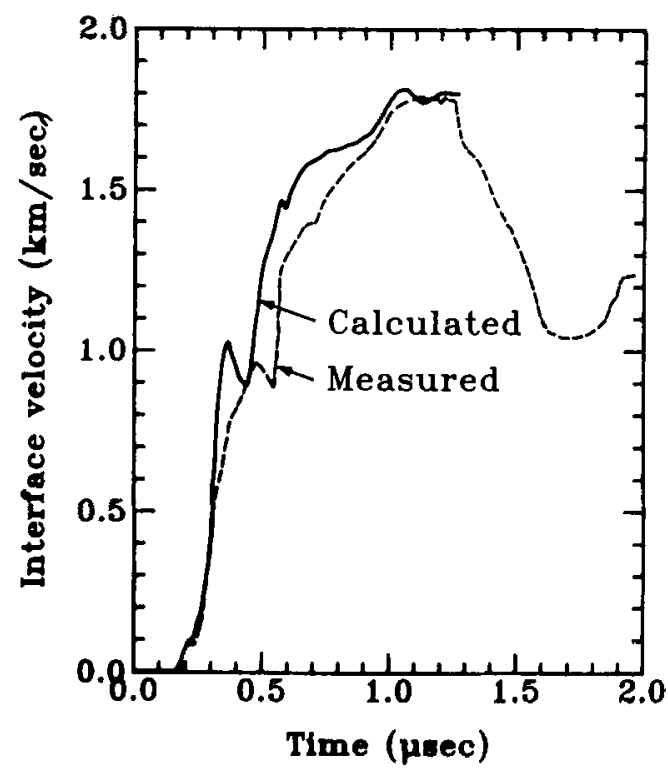

Figure 5 - Experiment n"24 - comparison between experimental and numerical particle velocity vergus time with numerical treatment of MIVAF Bpall. 
to spall. Micrographic examinations carried out on other MIVAFa ravantexi a deficiency in the adherence between the first two parts of the MIVARs. So we have added to the previous numerical simulation $\mathrm{mm}$, the numerical treatment of a void 0.1 min= thick between these first two partg. It can be seen in firure 5 that this model provides a reasonably accurate representation of the experimental data.

\section{5 - cancuusion}

A ramp-wave generating material called MIVAR has been developex uging a powder me= tallurgical technique know as "slurry paint technique". The eff'iciengy of this material has been proved up to $84 \mathrm{GPa}$ by plate-impact experiments where the MIVAFta were projected against target materials in which particle velooities vergua time protiles were measured by means of a VISAR interferometer. A moxdel of hydrodynamis bekn= vior of the MVAR was elaborated and numerical Bimulation carried out using this model confirmed structural defects of this material. A more efficiont MIVAF is pFe= sently under development.

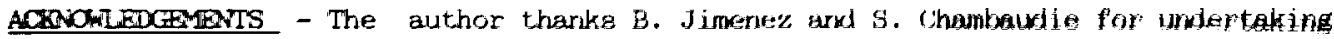
the experiments and $Y$. Lagarde for hia help in mumerical nimulations.

\section{FEFEREWCES}

11/ Berker, L.M., in : Shook Waveg in Cordenged Mattar, ad, J.R, Ashy et al, (NoF= th-Holl land, Hmeterdasi 1984,217 .

12. Jeandin, M., private cormuliteation.

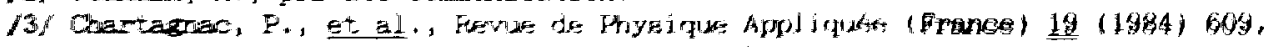

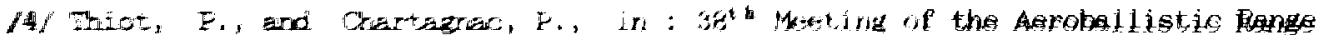

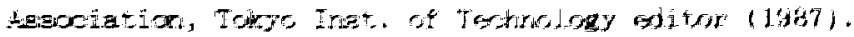

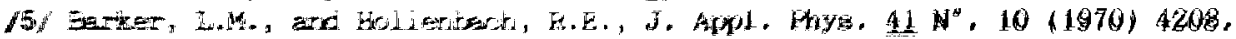

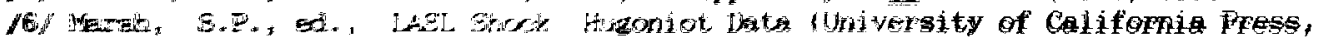
Beriketey $1900,13 f$.

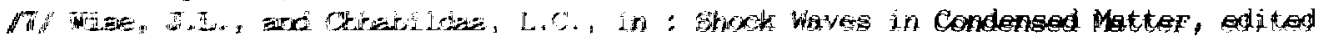

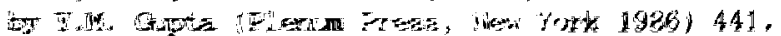

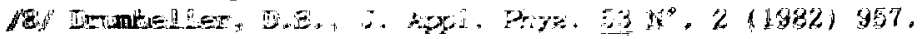

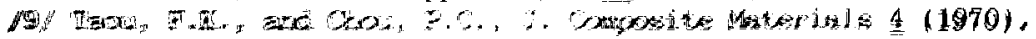

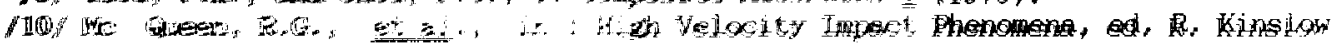

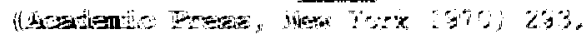

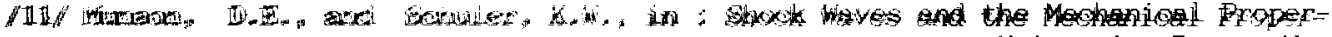

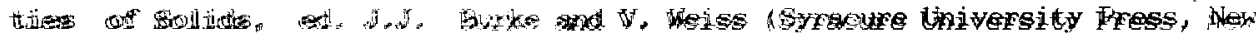

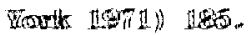

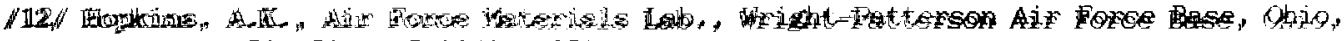

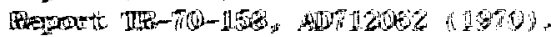

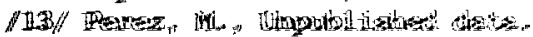

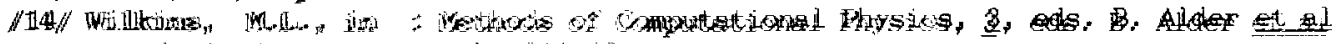

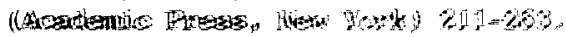

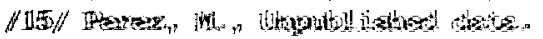

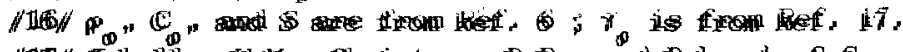

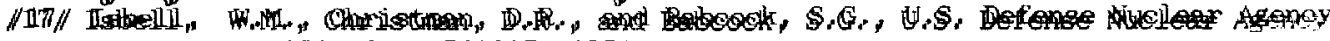
25011-6,

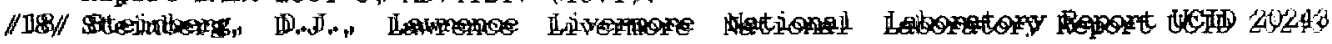
(11984)).. 